\title{
Complement C5 Contributes to Brain Injury After Subarachnoid Hemorrhage
}

\author{
Bart J. van Dijk ${ }^{1,2}$ • Joost C.M. Meijers ${ }^{3,4}$ - Anne T. Kloek ${ }^{5}$ - Veronique L. Knaup ${ }^{3}$ - Gabriel J.E. Rinkel ${ }^{2}$ - B. Paul Morgan ${ }^{6}$. \\ Marije J. van der Kamp ${ }^{1}$ - Koji Osuka ${ }^{7}$. Eleonora Aronica ${ }^{8}$ - Ynte M. Ruigrok ${ }^{2}$. Diederik van de Beek ${ }^{5}$. \\ Matthijs Brouwer ${ }^{5}$ - Marcela Pekna ${ }^{9}$. Elly M. Hol ${ }^{1,10} \cdot$ Mervyn D.I. Vergouwen $^{2}$
}

Received: 5 June 2019 / Revised: 29 October 2019 / Accepted: 19 November 2019 / Published online: 6 December 2019

(C) The Author(s) 2019

\begin{abstract}
Previous studies showed that complement activation is associated with poor functional outcome after aneurysmal subarachnoid hemorrhage (SAH). We investigated whether complement activation is underlying brain injury after aneurysmal SAH $(n=7)$ and if it is an appropriate treatment target. We investigated complement expression in brain tissue of aneurysmal SAH patients $(n=$ 930) and studied the role of common genetic variants in C3 and C5 genes in outcome. We analyzed plasma levels $(n=229)$ to identify the functionality of a single nucleotide polymorphism (SNP) associated with outcome. The time course of C5a levels was measured in plasma $(n=31)$ and CSF $(n=10)$. In an SAH mouse model, we studied the extent of microglia activation and cell death in wild-type mice, mice lacking the $\mathrm{C} 5$ a receptor, and in mice treated with $\mathrm{C} 5$-specific antibodies ( $n=15$ per group). Brain sections from aneurysmal SAH patients showed increased presence of complement components $\mathrm{C} 1 \mathrm{q}$ and $\mathrm{C} 3 / \mathrm{C} 3 \mathrm{~b} / \mathrm{iC} 3 \mathrm{~B}$ compared to controls. The complement component 5 (C5) SNP correlated with C5a plasma levels and poor disease outcome. Serial measurements in CSF revealed that C5a was $>1400$-fold increased 1 day after aneurysmal SAH and then gradually decreased. C5a in plasma was 2-fold increased at days 3-10 after aneurysmal SAH. In the SAH mouse model, we observed a $\approx 40 \%$ reduction in both microglia activation and cell death in mice lacking the $\mathrm{C} 5 \mathrm{a}$ receptor, and in mice treated with $\mathrm{C} 5$-specific antibodies. These data show that $\mathrm{C} 5$ contributes to brain injury after experimental SAH, and support further study of C5-specific antibodies as novel treatment option to reduce brain injury and improve prognosis after aneurysmal SAH.
\end{abstract}

Keywords Aneurysmal subarachnoid hemorrhage $\cdot$ Complement system $\cdot$ Brain injury

Electronic supplementary material The online version of this article (https://doi.org/10.1007/s12975-019-00757-0) contains supplementary material, which is available to authorized users.

Mervyn D.I. Vergouwen

m.d.i.vergouwen@umcutrecht.nl

1 UMC Utrecht Brain Center, Department of Translational Neurosciences, University Medical Center Utrecht, Utrecht University, Heidelberglaan 100, Utrecht, The Netherlands

2 UMC Utrecht Brain Center, Department of Neurology and Neurosurgery, University Medical Center Utrecht, Utrecht University, Heidelberglaan 100, Utrecht, The Netherlands

3 Department of Experimental Vascular Medicine, Academic Medical Center, Meibergdreef 9, Amsterdam, The Netherlands

4 Department of Plasma Proteins, Sanquin Research, Plesmanlaan 125, Amsterdam, The Netherlands

5 Department of Neurology, Amsterdam Neuroscience, Academic Medical Center, Meibergdreef 9, Amsterdam, The Netherlands
6 Systems Immunity Research Institute, Cardiff University, Heath Park, Cardiff, UK

7 Department of Neurological Surgery, Aichi Medical University, 1-1 Karimatayazako, Aichi, Japan

8 Department of Neuropathology, Academic Medical Center, Meibergdreef 9, Amsterdam, The Netherlands

9 Department of Clinical Neuroscience, Institute of Neuroscience and Physiology, Sahlgrenska Academy at University of Gothenburg, Medicinaregatan 9A, Gothenburg, Sweden

10 Netherlands Institute for Neuroscience, Institute of the Royal Netherlands Academy of Arts and Sciences, Meibergdreef 47, Amsterdam, The Netherlands 


\section{Introduction}

Aneurysmal SAH is a devastating subtype of stroke, caused by rupture of an aneurysm of an intracranial artery in the subarachnoid space. Although the prognosis after aneurysmal SAH has improved over the last decades, 90-day case fatality is still around 30\% in hospital-based studies [1]. The most important determinant of poor functional outcome after aneurysmal SAH is early brain injury directly related to the initial bleeding $[1,2]$. Other major determinants of poor functional outcome are rebleeding of the aneurysm and delayed cerebral ischemia, which may occur 4-14 days after the initial hemorrhage $[1,3]$. No treatment exists for early brain injury, while the effect of calcium antagonist nimodipine in preventing delayed cerebral ischemia is only modest [4]. Therefore, new treatment options are needed to reduce brain injury after SAH.

Poor functional outcome after SAH can partially be predicted using models that include factors such as age, World Federation of Neurological Surgeons (WFNS) scale at admission, and premorbid history of hypertension [5]. However, these models do not take into account the inflammatory response after $\mathrm{SAH}$, which is considered to play a key role in the pathogenesis of early brain injury and delayed cerebral ischemia after aneurysmal SAH $[6,7]$. The inflammatory response after SAH is independently associated with poor clinical condition on admission, delayed cerebral ischemia, disability, and death $[6,8,9]$. The inflammatory response in the brain is reflected by the activation of microglia and astrocytes [10]. The complement system may be a major component of this acute injury induced neuroinflammation after aneurysmal SAH. The classical pathway of the complement system is initiated by C1q, which then activates a cascade of other soluble or membrane bound proteins. Activation of the complement system leads to the cleavage of $\mathrm{C} 5$, resulting in $\mathrm{C} 5 \mathrm{a}$ and the lytic C5b-9 membrane attack complex. Anaphylatoxins $\mathrm{C} 3 \mathrm{a}$ and $\mathrm{C} 5 \mathrm{a}$ are important proinflammatory mediators and have the potential to produce vasoconstriction and activate coagulation by aggregation of platelets and regulation of tissue factor activity [11-15]. All these processes occur after aneurysmal SAH and are associated with early brain injury and delayed cerebral ischemia [16-21]. Plasma levels of mannose-binding lectin, $\mathrm{C} 3 \mathrm{a}$, and $\mathrm{C} 5 \mathrm{a}$ early after SAH correlate with outcome at discharge $[22,23]$. Despite the observed associations between complement activation and measures of brain injury after $\mathrm{SAH}$, it remains unclear if these are causal relationships. If so, this would represent an appealing target to decrease brain injury and improve prognosis after SAH.

We investigated the role of complement activation after SAH. In an autopsy study, we examined local complement expression in brains of patients who died from aneurysmal $\mathrm{SAH}$. We evaluated the association between common complement component polymorphisms and functional outcome and delayed cerebral ischemia, and elucidated the time-course of complement activation in CSF and plasma after SAH using serial measurements. We then confirmed our results in a $\mathrm{SAH}$ mouse model and studied whether treatment with a C5specific monoclonal antibody affects brain injury after SAH.

\section{Methods}

\section{Autopsy Study}

We used autopsy material from seven SAH patients (two males, five females, median age 56 years (range 34-77 years)) who died within 11 days after aneurysmal SAH. All patients had delayed cerebral ischemia [3]. We isolated cortical areas with both white and gray matter. From autopsy material from five control patients (three males, two females, median age 72 years (range 52-75 years)) who died from nonneurological causes (myocardial infarction: $n=3$; heart failure: $n=1$; pulmonary embolism: $n=1$ ), we isolated corresponding areas. Sections were stained with hematoxylin and eosin to distinguish infarcted from non-infarcted areas. For analysis, only non-infarcted areas were used. Complement component $\mathrm{Clq}$ acts as the initiating molecule in the classical pathway of the complement cascade, whereas $\mathrm{C} 3 \mathrm{~b}$ and $\mathrm{iC} 3 \mathrm{~b}$ are biologically active fragments of $\mathrm{C} 3$, a central molecule in the complement system. Deposition of $\mathrm{C} 3 / \mathrm{C} 3 \mathrm{~b} / \mathrm{iC} 3 \mathrm{~b}$ in the tissue indicates that the complement pathway reached a proinflammatory state [24]. We performed immunohistochemistry to investigate the presence of $\mathrm{Clq}$ (polyclonal rabbit, antihuman C1q complement, \#F0254, DAKO, 1:200) and C3/ $\mathrm{C} 3 \mathrm{~b} / \mathrm{iC} 3 \mathrm{~b}$ (polyclonal rabbit, anti-human $\mathrm{C} 3 \mathrm{c}$ complement, \#F0201, DAKO, 1:100). We were unable to evaluate the presence of C5a or C5b-9 (Membrane Attack Complex), as these antibodies do not work on the paraffin-embedded postmortem material. The immunohistochemistry of $\mathrm{C} 1 \mathrm{q}$ and $\mathrm{C} 3 / \mathrm{C} 3 \mathrm{~b} /$ $\mathrm{iC} 3 \mathrm{~b}$ on human brain sections resulted in heterogenous staining patterns, as shown in high magnification $(\times 100)$ images in Supplementary Fig. 1. Optical density measurements were used for quantitative assessments. Images were analyzed with FIJI software (ImageJ 2.0.0). After manually selecting the entire non-infarcted area per brain slide, selections were automatically quantified, expressed as a mean total of -log transformed grayscales, to calculate a mean per patient. The investigators who analyzed the immunohistochemistry images were blinded to the experimental group.

\section{Genotyping Study}

The cohort of the genetic study consisted of 930 patients who were admitted between 1983 and 2011 to the University Medical Center Utrecht, the Netherlands, which is a tertiary referral center for patients with SAH (Table 1). We used the University Medical Center Utrecht Subarachnoid 
Table 1 Patient characteristics

Cohort $(N=930)$

$$
\begin{array}{r}
\text { Me } \\
\text { Fe } \\
1 \\
2 \\
3 \\
4 \\
5
\end{array}
$$

Median age (year, interquartile range)

Female sex (number, \%)

WFNS grading scale on admission (number/total, \%)

1

2

3

4

5

Location of aneurysm in anterior circulation (number/total, \%)

In-hospital complications (number/total, \%)

Rebleeding

Clinical deterioration due to delayed cerebral ischemia

Glasgow Outcome Scale Score at 3 months (\%)

1. Death

2. Vegetative state

3. Severe disability

4. Moderate disability

5. Good recovery
$50(43-59)$

$653(70)$

481/905 (53)

$188 / 905(21)$

$60 / 905(7)$

$115 / 905$ (13)

$61 / 905(7)$

$802 / 911(88)$

125/914 (14)

174/913 (19)

$73(8)$

$4(0)$

$112(12)$

224 (24)

$517(56)$
Hemorrhage database, which is a prospectively collected database of consecutive patients with confirmed SAH, to collect the following variables: age, sex, clinical condition on admission according to the WFNS grading scale [25], aneurysm location, the occurrence of rebleeding and delayed cerebral ischemia, and functional outcome. After centrifugation of blood samples, the cell pellets were used to extract DNA for genotyping. The primary outcome was poor functional outcome, which was defined as a Glasgow Outcome Scale score of 1-3, 3 months after ictus [26]. Secondary outcome was clinical deterioration due to delayed cerebral ischemia, for which we used the definition that was proposed by an international multidisciplinary research group [3]. The occurrence of rebleeding was recorded between admission and aneurysm treatment, and defined as a sudden clinical deterioration with signs of increased hemorrhage on CT scan compared with previous CT imaging or found at autopsy, or a sudden clinical deterioration suspect for rebleeding with fresh blood in the ventricular drain in which no CT scan or autopsy was obtained. During collection of clinical data, the investigators were blinded for the results of genotyping.

\section{Genotyping}

The following common allele variants with a frequency of $>$ 5\% were investigated: C3 rs1047286, C3 rs2230199, and C5 rs17611. Genotyping was done using TaqMan SNP Genotyping Assays with the Lightcycler® 480. In case of unsuccessful genotyping of C5 rs17611, we used data from a previous genome-wide association study, which partly included the same patients as in the present study [27]. Due to the supplementary genome-wide association study data, genotype success rate for the C5 rs17611 SNP increased from 94.1 to $98.0 \%$. Genotyping was performed on coded DNA samples, so clinical information remained unknown to the laboratory personnel.

\section{C5a Levels in Plasma of Genotyped Patients}

To determine the relationship between the C5 rs17611 SNP and $\mathrm{C} 5 \mathrm{a}$ levels in plasma, we used plasma samples in a subset of 229 patients who presented with aneurysmal SAH between 2007 and 2011 (63 males, 176 females, median age 57 years (range 19-88 years)). Blood samples were obtained in EDTA tubes between days 1 and 14 after ictus. The samples were centrifuged and C5a levels in plasma were measured with the use of Human Complement C5a ELISA Kit (LifeSpan Biosciences) according to the manufacturers' instructions.

\section{Serial Measurement of C5a in CSF and Plasma}

We performed serial blood withdrawals in 31 patients with aneurysmal SAH (13 males, 18 females, median age 53 years (range 32-74 years)) and single measurements in 17 healthy control patients ( 6 males, 11 females, median age 53 years (range 30-63 years)). Blood samples in SAH patients were obtained in citrate tubes on days $1,3,5,7,10,14$, and 17 ( \pm 1 day), with day of ictus defined as day 0 . The samples were centrifuged and plasma $\mathrm{C} 5 \mathrm{a}$ levels were measured with the use of a C5a EIA kit (Quidel) according to the manufacturers' 
guidelines (standard curves $R^{2}$ ranging from 0.9998 to 1, lower limit of detection $0.05 \mathrm{ng} / \mathrm{mL}$ ).

CSF samples were collected from 10 patients with aneurysmal SAH (three males, seven females, median age 57 years (range 41-75 years)) and three controls in whom CSF was collected during surgery for an unruptured aneurysm (one male, two females, ages 49, 60, and 60 years). In 6 patients, CSF samples were collected from external ventricular drains and in 4 patients from lumbar drains. CSF was sampled on days $1,3,5,7,10,12$, and 14 after SAH with day of ictus defined as day 0 . All CSF samples were immediately centrifuged upon collection, and the supernatants were stored at $80^{\circ} \mathrm{C}$ until analysis. C5a levels were measured with the use of a C5a EIA kit (Quidel) according to the manufacturer's guidelines.

\section{SAH Animal Model}

To model SAH in mice, we applied the prechiasmatic blood injection model as described previously, with injection of $60 \mu \mathrm{L}$ of blood in the prechiasmatic cistern [28, 29]. Body temperature was maintained at $37{ }^{\circ} \mathrm{C}$. Cerebral blood flow was measured between $7.5 \mathrm{~min}$ prior to and up to $15 \mathrm{~min}$ after blood injection, with a laser Doppler flow meter (BLF22; Transonics Systems, New York, NY, USA). The success of SAH creation was confirmed by a sharp reduction in cerebral blood flow during blood injection. Mean cerebral blood flow during blood injection dropped to $\leq 25 \%$ of baseline in all groups, which is a reflection of an acute increase in intracranial pressure that is also seen in patients with aneurysmal $\mathrm{SAH}$. Mice were killed $48 \mathrm{~h}$ after blood injection. After intracardiac perfusion-fixation with $4 \%$ paraformaldehyde in PBS, brains were removed and post-fixed for $48 \mathrm{~h}$ in $4 \%$ paraformaldehyde in PBS, pH 7.4. Coronal cuts were made with a mouse brain matrix (Zivic Instruments, Pittsburgh, PA, USA). Slices were dehydrated and embedded in paraffin, and cut into $7-\mu \mathrm{m}$ sections with a microtome.

The following experimental groups were investigated: (a) wild-type (WT) mice (BALB/c, male, $n=15)$ with prechiasmatic injection of $60 \mu \mathrm{L}$ of blood from a donor WT mouse (BALB/c, male, $n=15$ ); (b) WT mice (BALB/c, male, $n=15$ ) with prechiasmatic injection of $60 \mu \mathrm{L}$ of blood from a donor WT mouse (BALB/c, male, $n=15)$ and with a subsequent intraperitoneal injection of a neutralizing monoclonal antibody directed against murine C5 (20 min after creation of SAH, $1 \mathrm{mg}$ per mouse; clone BB5.1; [30]; and (c) C5aR ${ }^{-/}$mice (C.129S4(B6)-C5arl $1^{\text {tmlCge }} / \mathrm{J}, 15$ times back crossed to BALB/c, obtained from the Jackson Laboratory, male, $n=15$ ) with prechiasmatic injection of $60 \mu \mathrm{L}$ of blood from a donor $C 5 a R^{-/-}$mouse, male, $n=15$ ). All mice were 2 months of age. The experiments were performed in random order.

\section{Immunocytochemistry}

Iba1 and cleaved caspase-3 immunofluorescence imaging was performed on coronal $7-\mu \mathrm{m}$ sections that were taken $3 \mathrm{~mm}$ anterior to the cerebellum of the mice. Iba1 (polyclonal rabbit, 1:4000, \#019-19741, Wako), cleaved caspase 3 (polyclonal rabbit, Antibody \#9661, 1:100, Cell Signalling), and NeuN (monoclonal, 1:500, Mab377, Chemicon) were used as primary antibodies. Hoechst 33258 (1:1000, Sigma-Aldrich) was used to visualize cell nuclei. We selected four predefined areas of cerebral cortex to quantify protein expression. Images were taken with the use of an epifluorescence microscope $(\times 20$ objective, Axio Scope A1, Zeiss) and processed with the use of Axiovision (Zeiss). We calculated the threshold area percentage of Iba1-positive cells with the use of FIJI software (ImageJ, NIH). The investigators who analyzed Ibal and cleaved caspase 3-positive cells were blinded to the experimental group.

\section{Statistical Analysis-Autopsy Study}

Optical density values were presented as mean with SEM, compared between areas of SAH patients and controls, and analyzed with a Student's $t$ test for the C1q analysis and a Mann-Whitney test for the $\mathrm{C} 3 / \mathrm{C} 3 \mathrm{~b} / \mathrm{iC} 3 \mathrm{~b}$ analysis.

\section{Statistical Analysis-Genetic Analysis}

The number of patients in our cohort $(n=930)$ was based on a variant with a minor allele frequency of 0.36 and a study power of $>80 \%$, to detect an association of the variant with poor functional outcome with an odds ratio of $\geq 1.8$ (http://pngu.mgh.harvard.edu/ purcell/gpc/). We calculated whether the genotype frequencies concurred with the Hardy-Weinberg equilibrium by use of an $X^{2}$ test with one degree of freedom with a $p$ value of less than 0 . 05 to indicate significance. Differences in genotype frequencies were analyzed with a two-tailed $X^{2}$ test. Statistical analyses were performed with SPSS version 20.0 for Windows (IBM, Armonk, NY, USA). We calculated odds ratios with $95 \%$ confidence intervals and performed logistic regression analyses with adjustments for age, sex, and WFNS grading scale on admission to calculate adjusted odds ratio. C5a levels per genotype of the C5 SNP rs17611 were analyzed by the Kruskal-Wallis test followed by Dunn's multiple comparison test. Correlation between plasma C5a levels and functional outcome 3 months after ictus, measured with the Glasgow Outcome Scale, was analyzed by partial Spearman's rho correlation test and controlled for WFNS grading scale score on admission. 


\section{Statistical Analysis-Serial C5a Measurements in CSF and Plasma}

Concentrations were presented as mean with SEM. Means of each serial C5a measurement in plasma were compared with the mean of the controls, calculated with ANOVA followed by the Dunnett's multiple comparisons test. Each serial C5a measurement in CSF was compared with the controls, calculated with Kruskal-Wallis test, followed by the Dunn's multiple comparisons test.

\section{Statistical Analysis-Animal Experiments}

The number of mice $(n=15)$ was based on an assumed mortality rate of $6 \%$ (leaving 14 mice available for analysis), a minimum difference in extent of microglia/macrophage activation or cells undergoing apoptosis of $25 \%$ between groups with and without C5a ablation, a standard deviation of $20 \%$ in both groups, $5 \%$ error, and $80 \%$ power.

The results of Iba1 and cleaved caspase-3 immunofluorescence stainings were presented as means with SD. Differences between groups were calculated with Kruskal-Wallis test, followed by the Dunn's multiple comparisons test. Probability values of $<0.05$ were considered to be of statistical significance.

\section{Results}

\section{Complement Expression in Brains of SAH Patients}

In autopsy brain tissue from SAH patients and controls, we found a higher expression in SAH patients compared to controls of complement component C1q (control mean \pm SEM $0.129 \pm 0.007, n=5$, versus SAH mean \pm SEM $0.155 \pm 0.007$, $n=7 ; t=2.66, d f=10 ; p<0.05$, Fig. $1 \mathrm{a}$ and $\mathrm{b}$ ) and complement component $\mathrm{C} 3 / \mathrm{C} 3 \mathrm{~b} / \mathrm{iC} 3 \mathrm{~b}$ (control mean \pm SEM $0.114 \pm 0.001$ versus $\mathrm{SAH}$ mean $\pm \mathrm{SEM} 0.148 \pm 0.005 ; U=0, p<0.01$, Fig. $1 \mathrm{c}$ and $\mathrm{d}$ ). These results show that $\mathrm{C} 1 \mathrm{q}$ and $\mathrm{C} 3 / \mathrm{C} 3 \mathrm{~b} / \mathrm{iC} 3 \mathrm{~b}$ immunoreactivity is increased in the brain after SAH.

\section{Genetic Association Study of Common Allele Variants of the Complement C3 and C5 Genes}

Inter-individual differences in the inflammatory response resulting from common polymorphisms in the complement system may explain part of the heterogeneity in disease severity and outcome following aneurysmal SAH. Previously, it was shown that these polymorphisms are involved in central nervous system inflammation [31]. We performed a genetic association study to investigate if common allele variants in $\mathrm{C} 3$ and $\mathrm{C} 5$ genes are associated with functional outcome and delayed cerebral ischemia. Characteristics of the 930 patients included in the genetic study are shown in Table 1. Poor functional outcome, measured by the Glasgow Outcome Score 1-3 at 3 months, occurred in 189 of the 930 patients (20\%). Data on genotyping success rate are shown in Table 2. All genotype frequencies were in concurrence with the Hardy-Weinberg equilibrium.

The relationship between genotyping and outcome is shown in Table 3. The C3 SNP frequencies were similar in patients with poor and good functional outcome, and in patients with and without delayed cerebral ischemia. The C5 rs17611 allele A was associated with poor functional outcome (odds ratio 1.49; 95\% confidence interval 1.04-2.14; adjusted odds ratio 1.53; 95\% CI 1.02-2.28; Table 3), but not with delayed cerebral ischemia (odds ratio 1.09 ; $95 \%$ CI $0.78-1.52$; adjusted odds ratio 1.10 ; $95 \%$ confidence interval 0.79-1.55; Table 4).

Since the C5 rs17611 allele A was associated with poor functional outcome, we subsequently measured plasma C5a levels in 229 genotyped patients with SAH in blood samples drawn between days 1 and 14 after the hemorrhage. Patients carrying allele A of the C5 rs17611 SNP had lower plasma C5a levels (genotype AA median $5.3 \mathrm{ng} / \mathrm{mL}$ [95\% confidence interval $5.3-7.1 \mathrm{ng} / \mathrm{mL}$ ]; AG median $13.0 \mathrm{ng} / \mathrm{mL}$ [95\% confidence interval $13.1-16.0 \mathrm{ng} / \mathrm{mL}$ ]; GG median $19.3 \mathrm{ng} / \mathrm{mL}$ [95\% confidence interval $18.2-25.9 \mathrm{ng} / \mathrm{mL}$ ]; $H=117.9$, $p<0.0001$, Fig. 2a). No correlation was found between plasma C5a levels and poor functional outcome, measured by the Glasgow Outcome Scale, 3 months after subarachnoid hemorrhage (partial Spearman's rho correlation $-0.09, p=0.16$, controlled for WFNS grading scale on admission).

\section{Serial C5a Measurements in CSF and Plasma of Subarachnoid Hemorrhage Patients}

We investigated the time-course of plasma C5a levels in $31 \mathrm{pa}-$ tients with aneurysmal SAH. Blood samples were taken at days $1,3,5,7,10,14$, and 17 ( \pm 1 day) after aneurysmal SAH. Plasma C5a levels steadily increased with a peak on day 5 after SAH (control mean $\pm \mathrm{SEM} 7.8 \pm 0.9 \mathrm{ng} / \mathrm{mL}$; SAH day 5 mean $\pm \mathrm{SEM}$ $17.9 \pm 2.0 \mathrm{ng} / \mathrm{mL}, F=3.305, p<0.01)$ and dropped thereafter (Fig. 2b). Furthermore, we used serial CSF samples from 10 patients with aneurysmal SAH up to day 14 after ictus and single CSF samples from 3 controls with unruptured aneurysms. The CSF levels of C5a were $>1400$ times increased 1 day after aneurysmal SAH (control mean \pm SEM $0.05 \pm 0.03 \mathrm{ng} / \mathrm{mL}$; SAH day 1 mean \pm SEM $71.9 \pm 26.4 \mathrm{ng} / \mathrm{mL}, H=23.21, p<0.001$ ) and slowly decreased over time (Fig. 2c). These data show that complement activation is strongly increased in the acute phase of $\mathrm{SAH}$, in particular in the central nervous system.

\section{Functional Analysis of the Role of C5 and C5a in an SAH Mouse Model}

To investigate if $\mathrm{C} 5$ contributes to brain injury after SAH and to study the effect of C5-specific antibodies on the extent of brain injury, we used 3 groups of mice in which SAH was 

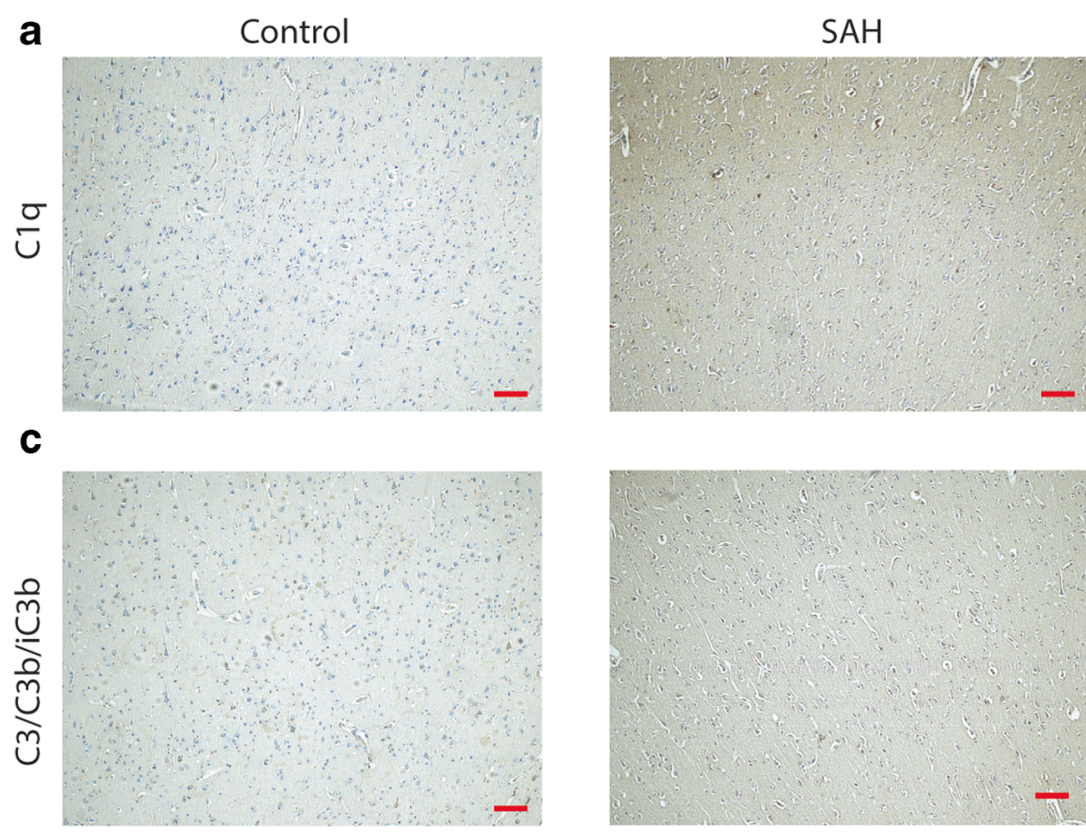

b

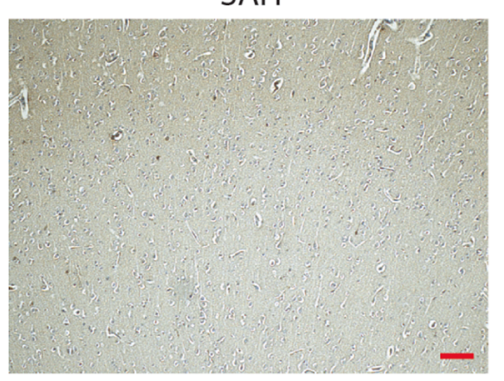

d
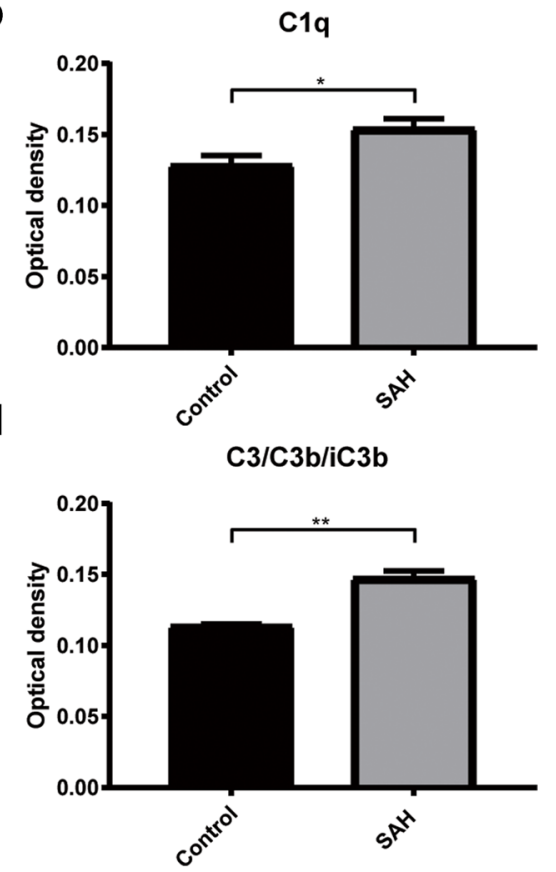

Fig. 1 Complement expression in human autopsy brain sections. a Representative images of immunohistochemical staining of $\mathrm{C} 1 \mathrm{q}$ on autopsy brain sections of a control patient, and a subarachnoid hemorrhage patient. b Average optical density measurements of C1q. c Representative images of immunohistochemical staining of $\mathrm{C} 3 / \mathrm{C} 3 \mathrm{~b} / \mathrm{iC} 3 \mathrm{~b}$

created with the prechiasmatic blood injection model [29]. We assessed microglia/macrophage activation and cell death $48 \mathrm{~h}$ after $\mathrm{SAH}$ induction. We found that Ibal expression, a microglia/macrophage marker, was reduced in the $\mathrm{C} 5 \mathrm{aR}^{-/-}$ mice compared to wild-type controls. Moreover, the mice treated with $\mathrm{C} 5$ specific antibody showed similar reduction in Iba1 expression $\left(\mathrm{C}^{2} \mathrm{aR}^{-/-}\right.$mean $\pm \mathrm{SD} 6.3 \pm 0.9 \%$; control $\mathrm{BALB} / \mathrm{c}$ mean $\pm \mathrm{SD} 10.8 \pm 2.1 \%$; C5 antibody treated mice mean $\pm \mathrm{SD} 6.7 \pm 1.0 \%$; Kruskal-Wallis, Dunn's post hoc, $H=$ 22.9, $p \leq 0.001$; Fig. 3a; quantified in Fig. 3c), indicating a reduced activation of microglia/macrophages, the innate immune cells of the brain. No difference in Iba1 expression between the $\mathrm{C} 5 \mathrm{aR}^{-/}$and $\mathrm{C} 5$ antibody treated wildtype mice was found, showing the potency of this treatment. Furthermore, the density of cells positive for cleaved caspase 3, marker for cells undergoing apoptosis, was reduced to a similar degree in the $\mathrm{C} 5 \mathrm{aR}^{-/-}$mice and mice treated with $\mathrm{C} 5$ antibody compared to wild-type controls $\left(\mathrm{C}^{2} \mathrm{aR}^{-/-}\right.$mean $\pm \mathrm{SD} 28 \pm 24$; on autopsy brain sections of a control patient, and a subarachnoid hemorrhage patient. d Average optical density measurements of C3/ C3b/iC3b. Scale bar: $100 \mu \mathrm{m}$, Student's $t$ test; ${ }^{*} p \leq 0.05 ; * * \leq 0.01$; mean \pm SEM

C5 antibody treated BALB/c mean \pm SD $26 \pm 16$; control BALB/c mean \pm SD $47 \pm 22$; Kruskal-Wallis, Dunn's post hoc, $H=8.6, p \leq 0.05$; Fig. 3b; quantified in Fig. $3 \mathrm{~d}$ ), indicating a reduction in the number of cells undergoing apoptosis. The majority of cleaved caspase 3-positive cells were also positive for NeuN, a neuronal marker (Fig. 3b).

\section{Discussion}

We are the first to show in a multilevel approach that complement factor $\mathrm{C} 5$ contributes to brain injury after SAH. We showed that the complement system is activated in the brain following $\mathrm{SAH}$, as reflected by the increased immunoreactivity for $\mathrm{C} 1 \mathrm{q}$ and $\mathrm{C} 3$ / $\mathrm{C} 3 \mathrm{~b} / \mathrm{iC} 3 \mathrm{~b}$ in brain tissue of patients who died after SAH compared with brain tissue of patients who died from nonneurological causes. C5 rs17611 SNP correlated with functional outcome after SAH and with plasma C5a levels, and that C5a

Table 2 Allele frequency, Hardy-Weinberg equilibrium, and genotyping success rate of common complement component polymorphisms in 930 patients with aneurysmal subarachnoid hemorrhage

\begin{tabular}{lllllllll}
\hline Gene & SNP ID & A $\%$ & B $\%$ & AA & AB & BB & HWE $p$ value & Success rate \\
\hline C3 & rs1047286 & $80.1 \%$ & $19.9 \%$ & 545 & 267 & 35 & $p=0.750$ & $91 \%$ \\
C3 & rs2230199 & $77.6 \%$ & $22.4 \%$ & 590 & 277 & 37 & $p=0.534$ & $97 \%$ \\
C5 & rs17611 & $43.7 \%$ & $56.3 \%$ & 182 & 432 & 297 & $p=0.274$ & $98 \%$ \\
\hline
\end{tabular}

$H W E$ Hardy-Weinberg equilibrium, SNP single nucleotide polymorphism 
Table 3 Genotyping analysis of common complement component polymorphisms in 741 patients with favorable outcome and 189 patients with unfavorable outcome

\begin{tabular}{|c|c|c|c|c|c|c|c|c|c|c|}
\hline \multirow[t]{2}{*}{ Gene } & \multirow[t]{2}{*}{ Allele } & \multirow[t]{2}{*}{ SNP ID } & \multicolumn{3}{|c|}{ Favorable outcome } & \multicolumn{3}{|c|}{ Unfavorable outcome } & \multirow[t]{2}{*}{ OR $(95 \% \mathrm{CI})$} & \multirow[t]{2}{*}{$\mathrm{aOR}(95 \% \mathrm{CI})$} \\
\hline & & & $\mathrm{AA}$ & $\mathrm{AB}$ & $\mathrm{BB}$ & AA & $\mathrm{AB}$ & $\mathrm{BB}$ & & \\
\hline $\mathrm{C} 3$ & $\mathbf{C} / \mathrm{T}$ & rs1047286 & 422 & 220 & 27 & 123 & 47 & 8 & $1.31(0.92-1.87)$ & $1.46(0.98-2.17)$ \\
\hline $\mathrm{C} 3$ & $\mathrm{C} / \mathrm{G}$ & rs2230199 & 462 & 227 & 28 & 128 & 50 & 9 & $0.84(0.59-1.18)$ & $0.75(0.51-1.11)$ \\
\hline $\mathrm{C} 5$ & $\mathbf{A} / \mathrm{G}$ & rs17611 & 144 & 333 & 249 & 38 & 99 & 48 & $1.49(1.04-2.14)$ & $1.53(1.02-2.28)$ \\
\hline
\end{tabular}

Allele in bold is used for analysis

$a O R$ adjusted odds ratio (adjusted for gender, age at time of ictus, and WFNS grading scale on admission), $C I$ confidence interval, $O R$ odds ratio, $S N P$ single nucleotide polymorphism

levels in CSF were markedly increased on day 1 after ictus and gradually decreased within the next 2 weeks. Plasma C5a levels were increased at a later stage, with a peak concentration around days 3-10 after ictus. In a mouse model of SAH, mice lacking $\mathrm{C} 5 \mathrm{a}$ receptor had $\mathrm{a} \approx 40 \%$ reduction of brain injury as reflected by reduced microglia/macrophage activation and cell apoptosis. This indicates that $\mathrm{C} 5 \mathrm{a}$ is involved in the pathogenesis of brain injury after experimental SAH. Similarly, mice treated with C5 neutralizing antibodies directly after the hemorrhage had reduced brain injury. As the mice were treated short after the induction of $\mathrm{SAH}$ and sacrificed 2 days after $\mathrm{SAH}$, this suggests that the inhibition of $\mathrm{C} 5$ has a long-lasting effect. These data indicate that C5 antibodies may be a promising new treatment option to decrease brain injury. Importantly, C5 antibodies are already used for other clinical indications [32-34]. Furthermore, studies showed that $\mathrm{C} 5$ antibodies are a promising new treatment option for patients with other neurological diseases, such as pneumococcal meningitis, neuromyelitis optica, and myasthenia gravis $[31,35,36]$.

The C5 rs17611 SNP correlated with poor functional outcome. This SNP has also been linked to poor outcome after pneumococcal meningitis [31], adverse cardiovascular outcomes [37], and periodontitis [38]. Recently, the functional basis for these disease associations was clarified [39]. Allele $\mathrm{G}$ of the $\mathrm{C} 5$ rs17611 SNP causes a missense mutation in the $\mathrm{C} 5$ gene, increases the rate of proteolytic activation of $\mathrm{C} 5$ and $\mathrm{C} 5 \mathrm{a}$ generation. As a result, patients carrying allele $G$ have increased C5a plasma levels [39]. This is in accordance with the results from our study, in which we found that patients carrying allele G of the C5 rs17611 SNP had higher plasma C5a levels than patients with allele A. Although patients with allele A had lower plasma C5a levels and were at increased risk of poor functional outcome, the plasma levels were not correlated with poor functional outcome. Since complement activation was much stronger upregulated in the CSF than in plasma, it remains to be investigated if $\mathrm{C} 5 \mathrm{a}$ levels in CSF correlate better with functional outcome than C5a levels in plasma.

There are a number of mechanisms by which complement activation can contribute to brain injury. The complement system has been linked to the regulation of synapse numbers [40]. In particular, complement components $\mathrm{Clq}$ and $\mathrm{C} 3$ have been implicated to facilitate the removal of synapses [41]. Unwanted synapses are tagged with $\mathrm{C} 1 \mathrm{q}$ and $\mathrm{C} 3$, thereby becoming eligible for elimination. Microglia recognize these components and start to remove the synapse [42]. Synaptic pruning by microglia occurs during development, but also in diseases such as glaucoma and Alzheimer's disease and after viral infection [41, 43, 44]. Therefore, complement activation in response to $\mathrm{SAH}$ may also induce excessive synapse pruning. However, while early complement components are involved in synapse elimination, the involvement of downstream components, such as C5 and C5a, remain to be investigated. Another mechanism by which complement activation may contribute to brain injury is by the membrane attack complex, formed by $\mathrm{C} 5 \mathrm{~b}-\mathrm{C} 9$ complexes. Hemolysis of blood in the CSF is thought to be complement system mediated by activation of the membrane attack complex $[45,46]$. The

Table 4 Genotyping analysis of common complement component polymorphisms in 725 patients without DCI and 169 patients with DCI

\begin{tabular}{|c|c|c|c|c|c|c|c|c|c|c|}
\hline \multirow[t]{2}{*}{ Gene } & \multirow[t]{2}{*}{ Allele } & \multirow[t]{2}{*}{ SNP ID } & \multicolumn{3}{|c|}{ No DCI } & \multicolumn{3}{|l|}{ DCI } & \multirow[t]{2}{*}{ OR $(95 \% \mathrm{CI})$} & \multirow[t]{2}{*}{$\mathrm{aOR}(95 \% \mathrm{CI})$} \\
\hline & & & $\mathrm{AA}$ & $\mathrm{AB}$ & $\mathrm{BB}$ & $\mathrm{AA}$ & $\mathrm{AB}$ & $\mathrm{BB}$ & & \\
\hline $\mathrm{C} 3$ & $\mathbf{C} / \mathrm{T}$ & rs1047286 & 432 & 214 & 28 & 103 & 47 & 7 & $0.93(0.67-1.30)$ & $0.95(0.67-1.33)$ \\
\hline $\mathrm{C} 3$ & $\mathrm{C} / \mathrm{G}$ & rs 223019 & 467 & 222 & 29 & 113 & 49 & 7 & $1.11(0.80-1.53)$ & $1.10(0.79-1.53)$ \\
\hline $\mathrm{C} 5$ & $\mathbf{A} / \mathrm{G}$ & rs17611 & 152 & 334 & 239 & 27 & 91 & 51 & $1.09(0.78-1.52)$ & $1.10(0.79-1.55)$ \\
\hline
\end{tabular}

Allele in bold is used for analysis

$a O R$ adjusted odds ratio (adjusted for gender, age at time of ictus, and WFNS grading scale on admission), $C I$ confidence interval, $D C I$ delayed cerebral ischemia, $O R$ odds ratio, SNP single nucleotide polymorphism 


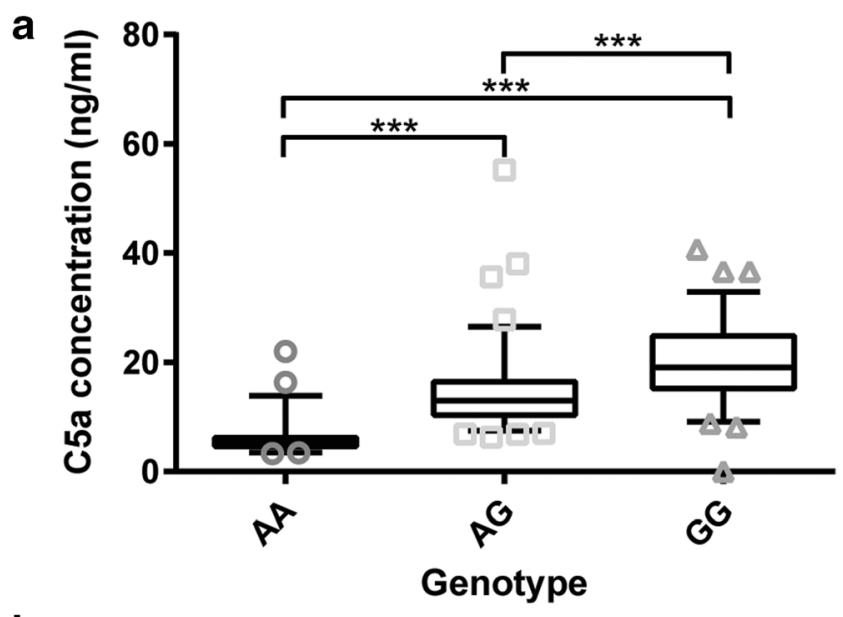

b

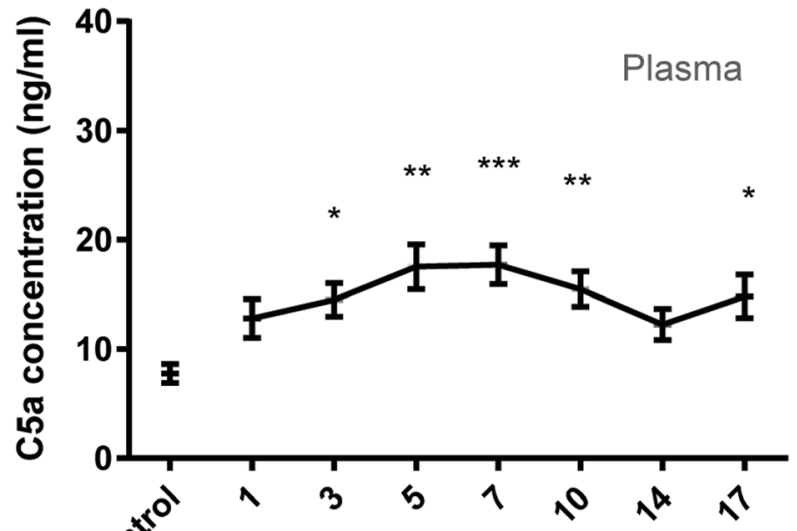

C

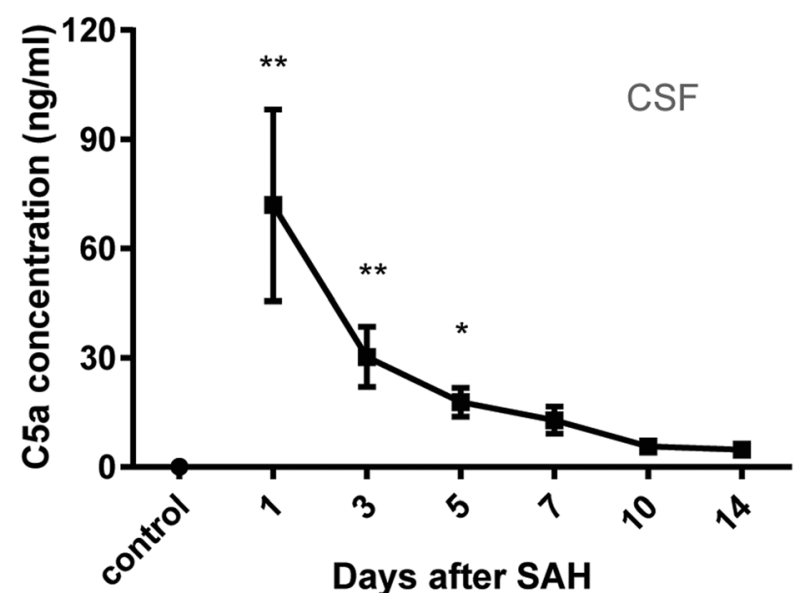

Fig. 2 C5a levels measured in plasma and CSF of aneurysmal subarachnoid hemorrhage patients. a Plasma C5a levels $(\mathrm{ng} / \mathrm{mL})$ of genotyped patients, grouped per genotype of the C5 single nucleotide polymorphism rs17611; blood samples were obtained between day 1 and day 14 postsubarachnoid hemorrhage; AA; $n=53$, AG; $n=98$, GG; $n=78$; Kruskal-Wallis, Dunn's multiple comparison, $* * * p \leq 0.001$, median $\pm 5-95$ percentile. b Sequentially measured C5a levels in plasma of aneurysmal subarachnoid hemorrhage patients $(n=31)$, versus plasma C5a levels of healthy controls $(n=17)$. Blood samples were taken on days $1,3,5,7,10,14$, and 17 ( \pm 1 day) after subarachnoid hemorrhage. $* p \leq 0.05, * * p \leq 0.01, * * * p \leq 0.001$, ANOVA, Dunnett's post hoc; mean \pm SEM. c Sequentially measured C5a levels in CSF of aneurysmal subarachnoid hemorrhage patients $(n=10)$ versus CSF C5a levels of patients with an unruptured aneurysm $(n=3)$. CSF obtained on days $1,3,5,7,10,12$, and 14 after subarachnoid hemorrhage. $* p \leq 0.05$, $* * p \leq 0.01$, Kruskal-Wallis test, Dunn's post hoc; mean \pm SEM membrane attack complex may also bind bystander cells, such as endothelial cells, ependymal cells and other brain cells, and thereby induce brain injury.

To address the specific involvement of $\mathrm{C} 5$ and $\mathrm{C} 5 \mathrm{a}$ in brain injury after $\mathrm{SAH}$, we used $\mathrm{C}_{5} \mathrm{aR}{ }^{-/-}$and wild-type mice treated with neutralizing antibody against C5. While the antibody treatment inhibits the generation of both activation products of $\mathrm{C} 5$, namely $\mathrm{C} 5 \mathrm{a}$ and $\mathrm{C} 5 \mathrm{~b}$, only the $\mathrm{C} 5 \mathrm{aR}$-mediated functions of $\mathrm{C} 5 \mathrm{a}$ are absent in the $\mathrm{C} 5 \mathrm{aR} \mathrm{R}^{-/}$mice. Our experimental data show that apoptosis and microglia activation are reduced in mice lacking $\mathrm{C} 5 \mathrm{aR}$ as well as mice treated with a single dose of neutralizing antibody against $\mathrm{C} 5$. These findings provide evidence for the detrimental role of $\mathrm{C} 5 \mathrm{a}$ in brain injury after $\mathrm{SAH}$ and are in line with previous studies in which $\mathrm{C} 5 \mathrm{aR}$ deficiency as well as treatment with a C5aR antagonist resulted in reduced apoptosis, increased cell viability, and reduced infarct volume after ischemic stroke [47, 48]. As C5a promotes neuronal apoptosis by acting directly through neuronal C5aR in-vitro [48], it is conceivable that the same neuronal mechanism is involved in brain injury after SAH.

$\mathrm{C} 5 \mathrm{aR}$ is also expressed by microglia which upregulate $\mathrm{C} 5 \mathrm{aR}$ in response to injury [49-51]. Thus, the reduced activation of microglia in the $\mathrm{C} 5 \mathrm{aR} \mathrm{R}^{-/}$and anti-C5 antibody treated mice may not only be an indirect effect of reduced cell death but may also be explained by direct effects of the intervention on these cells. In experimental spinal cord injury, C5aR signaling in the acute phase has been shown to contribute to tissue damage through local proinflammatory cytokine production and the recruitment of inflammatory monocytes/ macrophages [52]. As Iba1 is expressed in microglia as well as in blood born monocytes/macrophages, it is possible that recruited inflammatory cells together with activated microglia play a role in SAH-induced brain injury.

The effects of $\mathrm{C} 5 \mathrm{a}$ in the context of brain tissue injury may not be solely detrimental. C5a has been shown to be neuroprotective during neuronal maturation [53] and to protect neurons against glutamate-mediated toxicity [54]. Through the upregulation of microglial glutamate receptor GLT-1, C5a can also increase the capacity of microglia to clear excessive glutamate [55]. In addition, in the postacute stage after spinal cord injury, signaling through the $\mathrm{C} 5 \mathrm{a}-\mathrm{C} 5 \mathrm{aR}$ axis appears to serve a protective and/or reparative role [52]. Thus, in light of the potential beneficial effects of $\mathrm{C} 5 \mathrm{a}$, the timing of the therapeutic intervention targeting $\mathrm{C} 5 \mathrm{aR}$ after SAH may need to be carefully determined.

Interestingly, C5a can bind to Gpr77, also termed C5a-like receptor 2 (C5L2; [56]). The function of C5L2 is controversial, as both pro- and anti-inflammatory properties of this receptor have been described [56]. Our results that C5aR deficiency and inhibition of $\mathrm{C} 5$ activation reduced brain injury to the same extent support the contention that the deleterious effects of $\mathrm{C} 5 \mathrm{a}$ in the acute phase after SAH are mediated mainly by its canonical receptor $\mathrm{C} 5 \mathrm{aR}$. In addition to the release of $\mathrm{C} 5 \mathrm{a}$, the proteolytic 
a

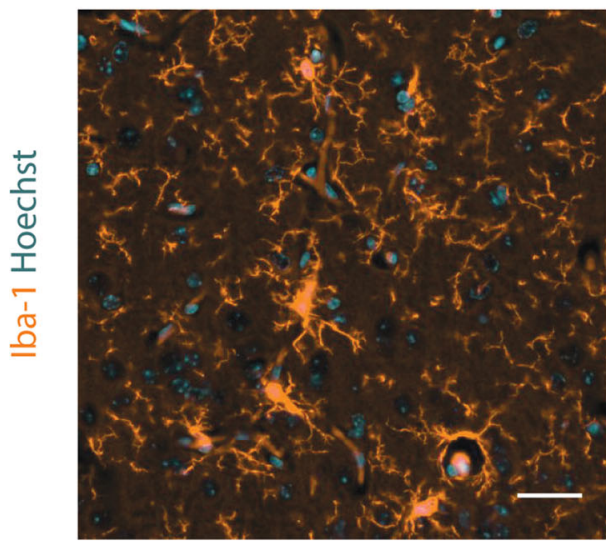

b

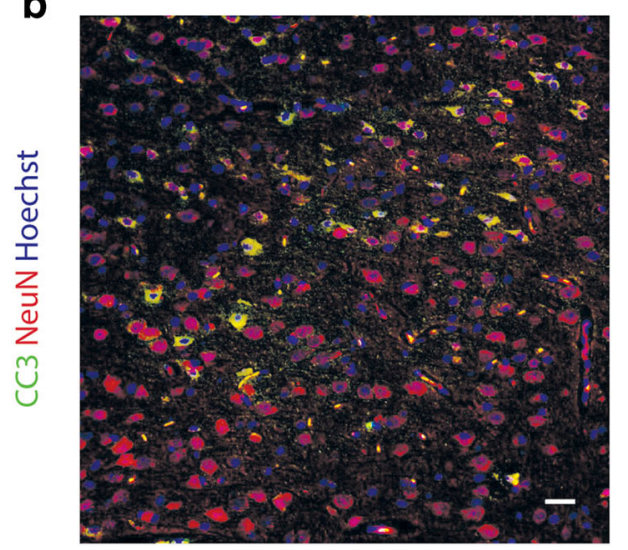

C

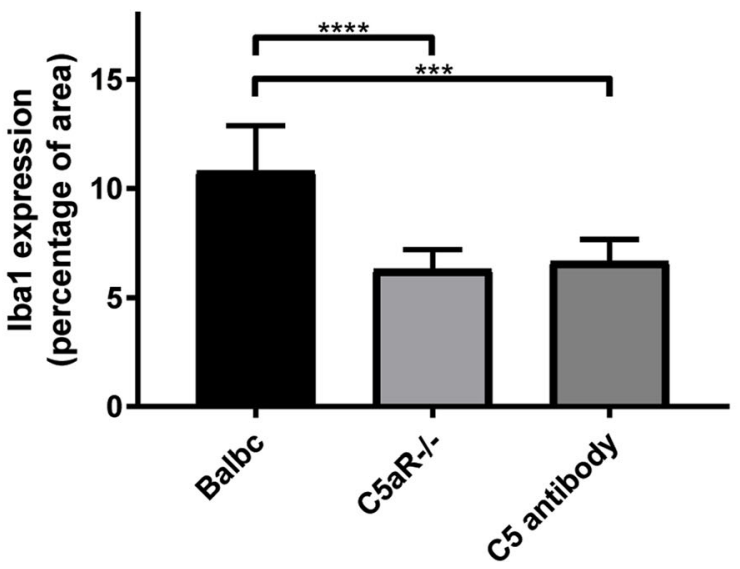

Fig. 3 C5 antibody treatment reduces brain injury in experimental subarachnoid hemorrhage. a Representative images of mouse cortex stained with antibody against Iba-1 (orange); cell nuclei in blue (Hoechst). b Representative images of mouse cortex stained with antibody against cleaved caspase 3 (CC3; green); $\mathrm{NeuN}$ (red) and cell nuclei in blue (Hoechst). c C5a receptor deficient $\left(\mathrm{C}^{2} \mathrm{aR}^{-/}\right)$and wild-type mice treated with $\mathrm{C} 5$-specific antibodies had a $>38 \%$ reduction in microglia/

activation of $\mathrm{C} 5$ triggers the formation of the membrane attack complex, C5b-9, leading to neuronal death through apoptosis [57] or cell lysis [55]. However, in light of our findings of the comparable effect of $\mathrm{C} 5 \mathrm{aR}$ deficiency and anti-C5 antibody treatment, a substantial contribution of C5b-9 to brain injury after SAH appears unlikely.
C5aR-/- Balb/c

C5 antibody treated Balb/c
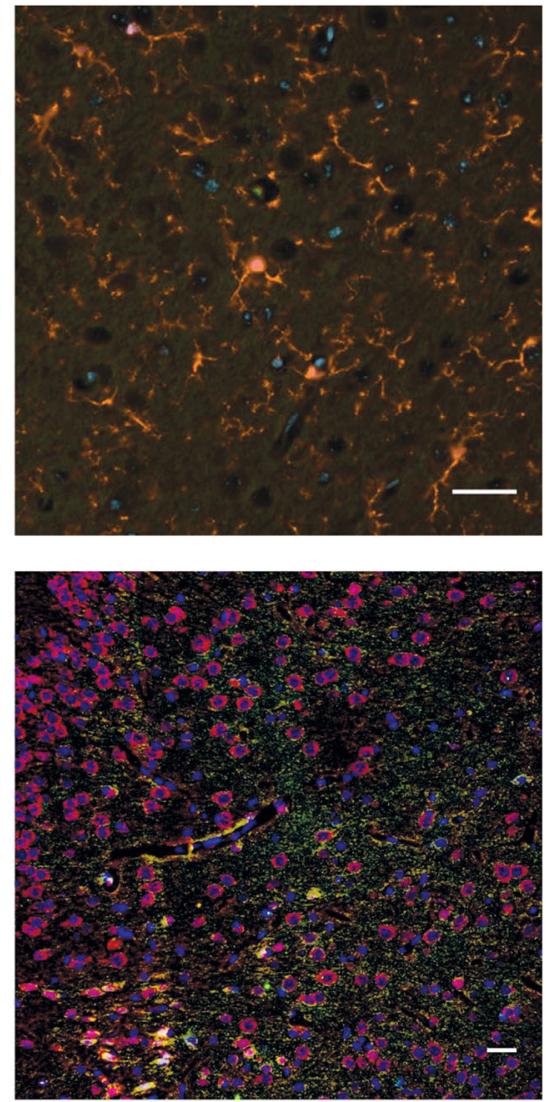

d

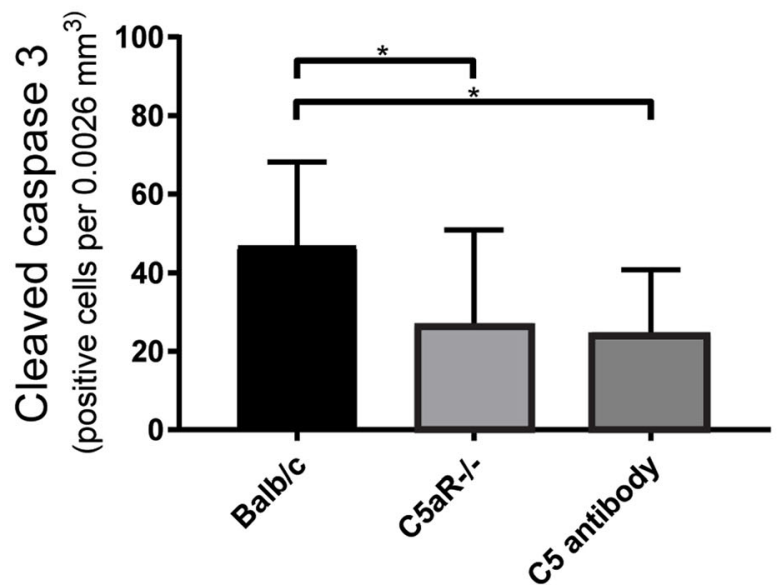

macrophage activation compared to untreated wild-type mice. KruskalWallis, Dunn's post hoc. d C5aR ${ }^{-/-}$mice and control BALB/c mice treated with $\mathrm{C} 5$-specific monoclonal antibodies had $>39 \%$ reduction in cells undergoing apoptosis, compared to untreated wild-type mice $48 \mathrm{~h}$ after subarachnoid hemorrhage. Kruskal-Wallis, Dunn's post hoc; $n=15$ mice per group; $* * * * p \leq 0.0001, * * * p \leq 0.001, * p \leq 0.05$; mean $\pm \mathrm{SD}$; scale bars $30 \mu \mathrm{m}$.

There are potential limitations to our study. The human brain tissue used in the autopsy study was from deceased patients. The increased expression of complement $\mathrm{Clq}$ and $\mathrm{C} 3 / \mathrm{C} 3 \mathrm{~b} / \mathrm{iC} 3 \mathrm{~b}$ may not reflect the situation of patients with a more favorable outcome. However, the CSF used to measure C5 levels was of patients of both favorable and unfavorable outcomes, and 
showed a sharp increase in complement C5 levels after SAH. This suggests activation of the complement cascade both in good and poor grade $\mathrm{SAH}$.

In conclusion, the present study highlights the role of C5a in the development of brain injury after SAH and identifies $\mathrm{C} 5$ antibodies as a potential novel treatment strategy to reduce brain injury after SAH.

Funding Information This study was financially supported by a personal grant from the Dutch Heart Foundation to MDIV (2011T18).

\section{Compliance with Ethical Standards}

Written informed consent was obtained from all participating patients or their legally authorized representatives, and controls. Approval for the genetic study was obtained from the Institutional Research Ethics Board, University Medical Center Utrecht, Utrecht, the Netherlands. All procedures performed in studies involving human participants were in accordance with the ethical standards of the Institutional Research Ethics Board and with the 1964 Helsinki declaration and its later amendments or comparable ethical standards. All animal experiments were approved by the Institutional Animal Care and Use Committee of the Academic Medical Center, Amsterdam, the Netherlands.

Competing Interests A patent was filed by the University Medical Center Utrecht, based on the data described in this manuscript (Methods of reducing brain injury after aneurysmal subarachnoid hemorrhage using anti-C5 or anti C5a antibodies [application number 62820860]).

Open Access This article is licensed under a Creative Commons Attribution 4.0 International License, which permits use, sharing, adaptation, distribution and reproduction in any medium or format, as long as you give appropriate credit to the original author(s) and the source, provide a link to the Creative Commons licence, and indicate if changes were made. The images or other third party material in this article are included in the article's Creative Commons licence, unless indicated otherwise in a credit line to the material. If material is not included in the article's Creative Commons licence and your intended use is not permitted by statutory regulation or exceeds the permitted use, you will need to obtain permission directly from the copyright holder. To view a copy of this licence, visit http://creativecommons.org/licenses/by/4.0/.

\section{References}

1. Vergouwen MD, Jong-Tjien-Fa AV, Algra A, Rinkel GJ. Time trends in causes of death after aneurysmal subarachnoid hemorrhage: a hospital-based study. Neurology. 2016;86:59-63.

2. Roos YB, de Haan RJ, Beenen LF, Groen RJ, Albrecht KW, Vermeulen M. Complications and outcome in patients with aneurysmal subarachnoid haemorrhage: a prospective hospital based cohort study in the Netherlands. J Neurol Neurosurg Psychiatry. 2000;68:337-41.

3. Vergouwen MD, Vermeulen M, van Gijn J, Rinkel GJ, Wijdicks EF, Muizelaar JP, et al. Definition of delayed cerebral ischemia after aneurysmal subarachnoid hemorrhage as an outcome event in clinical trials and observational studies: proposal of a multidisciplinary research group. Stroke. 2010;41:2391-5.

4. Dorhout Mees S, Rinkel GJ, Feigin VL, Algra A, van den Bergh WM, Vermeulen M, et al. Calcium antagonists for aneurysmal subarachnoid haemorrhage. Cochrane Database Syst Rev [Internet]. Wiley. 2007; Available from: http://onlinelibrary.wiley.com/doi/ 10.1002/14651858.CD000277.pub3/abstract.
5. Jaja BNR, Saposnik G, Lingsma HF, Macdonald E, Thorpe KE, Mamdani M, Steyerberg EW, Molyneux A, Manoel ALO, Schatlo B, Hanggi D, Hasan D, Wong GKC, Etminan N, Fukuda H, Torner J, Schaller KL, Suarez JI, Stienen MN, Vergouwen MDI, Rinkel GJE, Spears J, Cusimano MD, Todd M, Le Roux P, Kirkpatrick P, Pickard J, van den Bergh WM, Murray G, Johnston SC, Yamagata S, Mayer S, Schweizer TA, Macdonald RL; SAHIT collaboration. Development and validation of outcome prediction models for aneurysmal subarachnoid haemorrhage: the SAHIT multinational cohort study. BMJ. 2018;18;360:j5745. https://doi.org/10.1136/bmj. j5745.

6. Yoshimoto Y, Tanaka Y, Hoya K. Acute systemic inflammatory response syndrome in subarachnoid hemorrhage. Stroke. 2001;32: 1989-93.

7. Ibrahim GM, Morgan BR, Macdonald RL. Patient phenotypes associated with outcomes after aneurysmal subarachnoid hemorrhage: a principal component analysis. Stroke. 2014;45:670-6.

8. Dumont AS, Dumont RJ, Chow MM, Lin CL, Calisaneller T, Ley $\mathrm{KF}$, et al. Cerebral vasospasm after subarachnoid hemorrhage: putative role of inflammation. Neurosurgery. 2003;53:123-33.

9. Dhar R, Diringer MN. The burden of the systemic inflammatory response predicts vasospasm and outcome after subarachnoid hemorrhage. NeurocritCare. 2008;8:404-12.

10. van Dijk BJ, Vergouwen MD, Kelfkens MM, Rinkel GJ, Hol EM. Glial cell response after aneurysmal subarachnoid hemorrhage functional consequences and clinical implications. BiochimBiophysActa. 1862;2016:492-505.

11. Bjork J, Hugli TE, Smedegard G. Microvascular effects of anaphylatoxins C3a and C5a. JImmunol. 1985;134:1115-9.

12. Saadi S, Holzknecht RA, Patte CP, Stern DM, Platt JL. Complement-mediated regulation of tissue factor activity in endothelium. J Exp Med. 1995;182:1807-14.

13. Ikeda K, Nagasawa K, Horiuchi T, Tsuru T, Nishizaka H, Niho Y. C5a induces tissue factor activity on endothelial cells. Thromb Haemost. 1997;77:394-8.

14. Fortin JP, Bouthillier J, St-Pierre SA, Marceau F. Contractile effect of anaphylatoxin $\mathrm{C} 5 \mathrm{a}$ and of a mimetic peptide on the human umbilical artery: further evidence for leukocyte-dependent vasomotion. J Cardiovasc Pharmacol. 2002;40:815-21.

15. Guo RF, Ward PA. Role of C5a in inflammatory responses. Annu Rev Immunol. 2005;23:821-52.

16. Ohkuma H, Suzuki S, Kimura M, Sobata E. Role of platelet function in symptomatic cerebral vasospasm following aneurysmal subarachnoid hemorrhage. Stroke. 1991;22:854-9.

17. Hirashima Y, Nakamura S, Suzuki M, Kurimoto M, Endo S, Ogawa A, et al. Cerebrospinal fluid tissue factor and thrombinantithrombin III complex as indicators of tissue injury after subarachnoid hemorrhage. Stroke. 1997;28:1666-70.

18. Hirashima Y, Nakamura S, Endo S, Kuwayama N, Naruse Y, Takaku A. Elevation of platelet activating factor, inflammatory cytokines, and coagulation factors in the internal jugular vein of patients with subarachnoid hemorrhage. Neurochem Res. 1997;22: 1249-55.

19. Nissen JJ, Mantle D, Gregson B, Mendelow AD. Serum concentration of adhesion molecules in patients with delayed ischaemic neurological deficit after aneurysmal subarachnoid haemorrhage: the immunoglobulin and selectin superfamilies. J Neurol Neurosurg Psychiatry. 2001;71:329-33.

20. Frijns CJ, Kasius KM, Algra A, Fijnheer R, Rinkel GJ. Endothelial cell activation markers and delayed cerebral ischaemia in patients with subarachnoid haemorrhage. JNeurolNeurosurgPsychiatry. 2006;77:863-7.

21. Vergouwen MD, Bakhtiari K, van GN VM, Roos YB, Meijers JC. Reduced ADAMTS13 activity in delayed cerebral ischemia after aneurysmal subarachnoid hemorrhage. J Cereb Blood Flow Metab. 2009;29:1734-41. 
22. Mack WJ, Ducruet AF, Hickman ZL, Garrett MC, Albert EJ, Kellner CP, et al. Early plasma complement C3a levels correlate with functional outcome after aneurysmal subarachnoid hemorrhage. Neurosurgery. 2007;61:255-60.

23. Cai JY, Sun J, Yu ZQ. Serum mannose-binding lectin levels after aneurysmal subarachnoid hemorrhage. Acta Neurol Scand. 2016;134:360-7.

24. Ricklin D, Lambris JD. Complement in immune and inflammatory disorders: therapeutic interventions. J Immunol. 2013;190:3839-47.

25. Teasdale GM, Drake CG, Hunt W, Kassell N, Sano K, Pertuiset B, et al. A universal subarachnoid hemorrhage scale: report of a committee of the World Federation of Neurosurgical Societies. J Neurol Neurosurg Psychiatry. 1988;51:1457.

26. Jennett B, Teasdale G, Braakman R, Minderhoud J, Knill-Jones R. Predicting outcome in individual patients after severe head injury. Lancet. 1976;1:1031-4.

27. Yasuno K, Bilguvar K, Bijlenga P, Low SK, Krischek B, Auburger $\mathrm{G}$, et al. Genome-wide association study of intracranial aneurysm identifies three new risk loci. Nat Genet. 2010;42:420-5.

28. Sabri M, Ai J, Lakovic K, Macdonald RL. Mechanisms of microthrombosis and microcirculatory constriction after experimental subarachnoid hemorrhage. Acta Neurochir Suppl. 2013;115:185-92.

29. Sabri M, Ai J, Lass E, D'Abbondanza J, Macdonald RL. Genetic elimination of eNOS reduces secondary complications of experimental subarachnoid hemorrhage. J Cereb Blood Flow Metab. 2013;33:1008-14.

30. Frei Y, Lambris JD, Stockinger B. Generation of a monoclonal antibody to mouse C5 application in an ELISA assay for detection of anti-CS antibodies. Mol Cell Probes. 1987;1:141-9.

31. Woehrl B, Brouwer MC, Murr C, Heckenberg SG, Baas F, Pfister $\mathrm{HW}$, et al. Complement component 5 contributes to poor disease outcome in humans and mice with pneumococcal meningitis. J Clin Invest. 2011:121:3943-53.

32. Hillmen P, Hall C, Marsh JC, Elebute M, Bombara MP, Petro BE, et al. Effect of eculizumab on hemolysis and transfusion requirements in patients with paroxysmal nocturnal hemoglobinuria. $\mathrm{N}$ Engl J Med. 2004;350:552-9.

33. Rother RP, Rollins SA, Mojcik CF, Brodsky RA, Bell L. Discovery and development of the complement inhibitor eculizumab for the treatment of paroxysmal nocturnal hemoglobinuria. Nat Biotechnol. 2007;25:1256-64.

34. Legendre CM, Licht C, Muus P, Greenbaum LA, Babu S, Bedrosian C, et al. Terminal complement inhibitor eculizumab in atypical hemolyticuremic syndrome. N Engl J Med. 2013;368:2169-81.

35. Howard JF Jr, Barohn RJ, Cutter GR, Freimer M, Juel VC, Mozaffar T, et al. A randomized, double-blind, placebo-controlled phase II study of eculizumab in patients with refractory generalized myasthenia gravis. Muscle Nerve. 2013;48:76-84.

36. Pittock SJ, Lennon VA, McKeon A, Mandrekar J, Weinshenker BG, Lucchinetti CF, et al. Eculizumab in AQP4-IgG-positive relapsing neuromyelitis optica spectrum disorders: an open-label pilot study. Lancet Neurol. 2013;12:554-62.

37. Hoke M, Speidl W, Schillinger M, Minar E, Zehetmayer S, Schonherr M, et al. Polymorphism of the complement 5 gene and cardiovascular outcome in patients with atherosclerosis. Eur J Clin Invest. 2012;42:921-6.

38. Chai L, Song YQ, Zee KY, Leung WK. Single nucleotide polymorphisms of complement component 5 and periodontitis. J Periodontal Res. 2010;45:301-8.

39. Giles JL, Choy E, van den Berg C, Morgan BP, Harris CL. Functional analysis of a complement polymorphism (rs17611) associated with rheumatoid arthritis. J Immunol. 2015;194:3029-34.

40. Stephan AH, Barres BA, Stevens B. The complement system: an unexpected role in synaptic pruning during development and disease. Annu Rev Neurosci. 2012;35:369-89.
41. Stevens B, Allen NJ, Vazquez LE, Howell GR, Christopherson KS, Nouri N, et al. The classical complement cascade mediates CNS synapse elimination. Cell. 2007;131:1164-78.

42. Weinhard L, di Bartolomei G, Bolasco G, Machado P, Schieber NL, Neniskyte U, et al. Microglia remodel synapses by presynaptic trogocytosis and spine head filopodia induction. Nat Commun [Internet]. 2018; [cited 2019 Jan 7];9. Available from: http://www. nature.com/articles/s41467-018-03566-5.

43. Hong S, Beja-Glasser VF, Nfonoyim BM, Frouin A, Li S, Ramakrishnan S, et al. Complement and microglia mediate early synapse loss in Alzheimer mouse models. Science. 2016;352:7126.

44. Vasek MJ, Garber C, Dorsey D, Durrant DM, Bollman B, Soung A, et al. A complement-microglial axis drives synapse loss during virus-induced memory impairment. Nature. 2016;534:538-43.

45. Park CC, Shin ML, Simard JM. The complement membrane attack complex and the bystander effect in cerebral vasospasm. J Neurosurg. 1997;87:294-300.

46. Peterson JW, Kwun B-D, Teramura A, Hackett JD, Morgan JA, Nishizawa S, et al. Immunological reaction against the aging human subarachnoid erythrocyte. J Neurosurg. 1989:718-26.

47. Kim GH, Mocco J, Hahn DK, Kellner CP, Komotar RJ, Ducruet $\mathrm{AF}$, et al. Protective effect of $\mathrm{C} 5$ a receptor inhibition after murine reperfused stroke. Neurosurgery. 2008;63:122-5.

48. Pavlovski D, Thundyil J, Monk PN, Wetsel RA, Taylor SM, Woodruff TM. Generation of complement component C5a by ischemic neurons promotes neuronal apoptosis. FASEB J. 2012;26: 3680-90.

49. Gasque P, Singhrao SK, Neal JW, Gotze O, Morgan BP. Expression of the receptor for complement C5a (CD88) is up-regulated on reactive astrocytes, microglia, and endothelial cells in the inflamed human central nervous system. Am J Pathol. 1997;150:31-41.

50. van Beek J, Bernaudin M, Petit E, Gasque P, Nouvelot A, MacKenzie ET, et al. Expression of receptors for complement anaphylatoxins $\mathrm{C} 3 \mathrm{a}$ and $\mathrm{C} 5 \mathrm{a}$ following permanent focal cerebral ischemia in the mouse. Exp Neurol. 2000;161:373-82.

51. Orre M, Kamphuis W, Osborn LM, Jansen AH, Kooijman L, Bossers $\mathrm{K}$, et al. Isolation of glia from Alzheimer's mice reveals inflammation and dysfunction. Neurobiol Aging. 2014;35:2746-60.

52. Brennan FH, Gordon R, Lao HW, Biggins PJ, Taylor SM, Franklin $\mathrm{RJ}$, et al. The complement receptor C5aR controls acute inflammation and astrogliosis following spinal cord injury. J Neurosci. 2015;35:6517-31.

53. Benard M, Gonzalez BJ, Schouft MT, Falluel-Morel A, Vaudry D, Chan $\mathrm{P}$, et al. Characterization of $\mathrm{C} 3 \mathrm{a}$ and $\mathrm{C} 5 \mathrm{a}$ receptors in rat cerebellar granule neurons during maturation. Neuroprotective effect of C5a against apoptotic cell death. J Biol Chem. 2004;279:43487-96.

54. Osaka H, Mukherjee P, Aisen PS, Pasinetti GM. Complementderived anaphylatoxin $\mathrm{C} 5$ a protects against glutamate-mediated neurotoxicity. J Cell Biochem. 1999;73:303-11.

55. Persson M, Pekna M, Hansson E, Ronnback L. The complementderived anaphylatoxin C5a increases microglial GLT-1 expression and glutamate uptake in a TNF-alpha-independent manner. Eur J Neurosci. 2009;29:267-74.

56. Li R, Coulthard LG, Wu MC, Taylor SM, Woodruff TM. C5L2: a controversial receptor of complement anaphylatoxin, C5a. FASEB J. 2013;27:855-64.

57. Nauta AJ, Daha MR, Tijsma O, van de Water B, Tedesco F, Roos A. The membrane attack complex of complement induces caspase activation and apoptosis. Eur J Immunol. 2002;32:783-92.

Publisher's Note Springer Nature remains neutral with regard to jurisdictional claims in published maps and institutional affiliations. 